\title{
Carbohydrate Antigen 19-9 Predicts Synchronous Peritoneal Carcinomatosis in Patients with Colorectal Cancer
}

\author{
MANABU KANEKO ${ }^{1,2}$, SOICHIRO ISHIHARA ${ }^{2}$, KOJI MURONO ${ }^{2}$, KAZUHITO SASAKI $^{2}$, \\ KENSUKE OTANI $^{2}$, KOJI YASUDA ${ }^{2}$, TAKESHI NISHIKAWA ${ }^{2}$, TOSHIAKI TANAKA ${ }^{2}$, \\ TOMOMICHI KIYOMATSU ${ }^{2}$, KEISUKE HATA ${ }^{2}$, KAZUSHIGE KAWAI ${ }^{2}$, HIROAKI NOZAWA ${ }^{2}$, \\ HIROSHI NAKAYAMA ${ }^{1}$, TOSHIYUKI WATANABE ${ }^{1}$, SHIN SASAKI $^{1}$ and TOSHIAKI WATANABE ${ }^{2}$ \\ ${ }^{1}$ Department of Surgery, Omori Red Cross Hospital, Tokyo, Japan; \\ ${ }^{2}$ Department of Surgical Oncology, Faculty of Medicine, The University of Tokyo, Tokyo, Japan
}

\begin{abstract}
Background: Colorectal cancer (CRC) with peritoneal carcinomatosis (PC) has the worst prognosis among all types of metastases, but is difficult to diagnose. This study investigated whether preoperative serum carbohydrate antigen (CA) $19-9$ level can predict synchronous $P C$ in patients with primary CRC. Patients and Methods: The cases of 395 CRC patients who underwent primary lesion resection were retrospectively reviewed. Risk factors were evaluated by uni- and multivariate analyses from clinicopathological data. Results: In the univariate analysis, tumor invasion $(p<0.001)$, lymph node and hematogenous metastases $(p=0.037$ and $p<0.001$, respectively), and elevated preoperative serum CA19-9 level $(p<0.001)$ were associated with synchronous $P C$, and multiple regression analysis revealed that an elevated preoperative serum CA19-9 level was an independent risk factor for PC (odds ratio=5.03, 95\% confidence interval=1.29-19.60, $p=0.020)$. Conclusion: Elevated preoperative serum CA 19-9 level may be useful in predicting synchronous $P C$ in patients with $C R C$.
\end{abstract}

Colorectal cancer (CRC) is the third most frequently diagnosed cancer in males and the second in females worldwide; about 1.4 million new cases and nearly 700,000 deaths from CRC were reported in 2012 (1). Peritoneal carcinomatosis (PC) is not a rare manifestation in the natural course of CRC, and is associated with worse overall survival (2-4). The incidence of synchronous PC in patients with

Correspondence to: Dr. Manabu Kaneko, Department of Surgical Oncology, Faculty of Medicine, The University of Tokyo, 7-3-1 Hongo, Bunkyo-ku Tokyo 113-8655, Japan. Tel: +81 338155411, Fax: +81 338116822, e-mail: m.kaneko@fancy.ocn.ne.jp

Key Words: Carbohydrate antigen 19-9, peritoneal carcinomatosis, colorectal cancer, risk factor.
CRC is $3.6-15 \%$ (5-11), despite recent advances in early disease detection. Computed tomography (CT) is used for diagnosing PC; however, small metastatic nodules cannot always be detected by CT (12-15). As such, it is not unusual to find PC during the removal of the primary tumor.

Carbohydrate antigen (CA) 19-9 is a tumor marker often used in combination with carcinoembryonic antigen (CEA) in the management of patients with CRC. A previous study reported that a high preoperative serum CA 19-9 level was independently associated with high preoperative serum CEA level, lymph node metastasis, right colon cancer, large tumor size, and PC (16), suggesting that it provides important information for predicting the occurrence of PC. Another group reported younger age, advanced T-stage, poor differentiation grade, and right-sided tumor as risk factors for the presence of PC at the time of diagnosis (8). However, it is unclear whether the preoperative CA19-9 level is predictive of synchronous PC in patients with CRC.

To address this issue, the present study investigated whether an elevated preoperative serum CA19-9 level can predict synchronous $\mathrm{PC}$ in patients with CRC undergoing resection of the primary lesion.

\section{Patients and Methods}

Patient population. We retrospectively analyzed 395 patients with pathologically confirmed CRC (clinical stage I-IV), who underwent primary tumor resection with or without metastasectomy between January 2009 and December 2015 at the Department of Surgery, Omori Red Cross Hospital in Tokyo, Japan. Medical charts of all patients included in this study were retrieved from our registry, and clinicopathological data were collected. Factors included in the analyses were age, sex, American Society of Anesthesiologists (ASA) physical status, site of primary tumor, maximum tumor diameter, tumor depth, lymph node metastasis classified according to the Union for International Cancer Control guidelines (17), histology, lymphatic and venous involvement, hematogenous metastasis, PC, and preoperative serum CEA and CA19-9 levels. Patients underwent exploration of the abdominal cavity for macroscopic PC which, if 
present, was classified according to the Japanese Classification of Colorectal Carcinoma edited by the Japanese Society for Cancer of the Colon and Rectum (18). In the classification, peritoneal metastases were categorized into the following three groups according to PC status: P1, metastasis only to adjacent peritoneum; P2, a few metastases of the distant peritoneum; P3, numerous metastases of the distant peritoneum. Serum CEA and CA19-9 values were measured using ARCHITECT i2000 with ARCHITECT CEA or CA19-9 XR reagents, respectively (Abbott Laboratories, Abbott Park, IL, USA). CEA and CA19-9 levels of up to $5.0 \mathrm{ng} / \mathrm{ml}$ and $37.0 \mathrm{U} / \mathrm{ml}$, respectively, were taken as upper cut-off values for reference ranges. Patients were divided into two groups: those with and without synchronous PC. Clinical and pathological variables affecting the presence of synchronous PC were compared between the two groups. To investigate the impact of synchronous PC on the survival of patients with CRC, we carried out a subgroup analysis in patients with stage IV disease in which we compared 2-year overall survival rates between patients with and those without PC. The study protocol was approved by the Institutional Review Board of Omori Red Cross Hospital (Approval Number: 15-6).

Statistical analysis. Associations between the presence of synchronous PC and clinical and pathological parameters were assessed with the Fisher's exact test. Variables that were significant in the univariate analysis were examined in the multivariate analysis with the logistic regression test. Survival analyses were performed with the Kaplan-Meier method and log-rank test. All reported pvalues are two-tailed, and those less than 0.05 were considered significant. Data were analyzed using EZR v.1.24 for Windows software (Saitama Medical Center, Jichi Medical University, Saitama, Japan), which is a graphical user interface for R (The R Foundation for Statistical Computing, Vienna, Austria) (19).

\section{Results}

A total of 231 men $(58.5 \%)$ and 164 women (41.5\%) were included in the study, with a median age of 73 years (range $=30-94$ years). In total 67 patients $(17.0 \%$ ) had an elevated preoperative serum CA19-9 level. All 395 patients underwent exploration of the abdominal cavity for macroscopic PC and resection of the primary lesion with curative or palliative intent. There were 12 patients (3.0\%) with pathologically confirmed synchronous macroscopic PC. There were no significant differences among P1, P2, and P3 groups with respect to preoperative CA19-9 level; we, therefore, divided the 395 patients into two groups, with or without synchronous PC, for subsequent analyses. Demographic and baseline characteristics are summarized in Table I.

A comparison of clinical and pathological outcomes between patients with and without synchronous PC is shown in Table II. In univariate analyses, factors that were significantly associated with synchronous PC were greater tumor depth $(p<0.001)$ and number of metastatic lymph nodes $(p=0.037)$, presence of hematogenous metastases $(p<0.001)$, and elevated preoperative CA19-9 level $(p<0.001)$. There were no significant differences in terms of other factors between the two groups.
Results of the multiple logistic regression analysis to identify risk factors associated with synchronous macroscopic PC are shown in Table III. When parameters that were significant in univariate analyses were subjected to multivariate analysis, an elevated preoperative CA19-9 level [odds ratio $(\mathrm{OR})=5.03 ; 95 \%$ confidence interval $(\mathrm{CI})=1.29$ $19.60 ; p=0.020]$ was found to be a significant risk factor for synchronous PC. The presence of hematogenous metastases was also associated with synchronous PC $(\mathrm{OR}=3.29 ; 95 \%$ $\mathrm{CI}=0.88-12.30 ; p=0.076$ ).

To assess the impact of synchronous PC on the prognosis of patients with CRC, a subgroup analysis was carried out only on patients with metastatic disease (i.e. 50 patients with stage IV CRC). Patients with synchronous PC had worse 2year overall survival rates than those without synchronous PC $(82.6 \%$ vs. $33.3 \%, p<0.001)$ (Figure 1).

\section{Discussion}

$\mathrm{PC}$ at the time of initial presentation is not uncommon in $\mathrm{CRC}$; the associated refractory ascites, progressive intestinal obstruction, and intractable abdominal pain can negatively impact both survival and quality of life of patients (11). Furthermore, $20-50 \%$ of patients with recurrent CRC have metastasis confined to the peritoneal cavity (20), with approximately $30 \%$ dying as a result (7). Therefore, confirming the occurrence of PC is critical in CRC. The majority of patients with CRC with synchronous PC have hematogenous metastases and are exclusively treated with palliative care for symptom relief with or without chemotherapy (21). In this study, about $3.0 \%$ of patients were diagnosed with synchronous macroscopic PC, an incidence that is slightly lower than the $4.5 \%$ reported in the guidelines for treatment of CRC edited by the Japanese Society for Cancer of the Colon and Rectum (6). This was partly because our study did not include patients with stage IV disease who did not undergo primary lesion resection, whereas the data described in the guidelines included such patients. Of the patients with synchronous PC, 50\% had other metastatic diseases; only $16.7 \%$ of patients underwent curative resection. We found that patients with stage IV CRC with synchronous PC had a significantly worse prognosis than those without synchronous PC, in agreement with previous studies (2-4).

CA19-9 was originally isolated from a human colorectal cancer cell line as a derivative of lacto- $N$-fucopenteose II (sialyl-Lewis[a], hapten of human Lewis[a] blood-group determinant) (22). In this study, the preoperative serum CA19-9 level was elevated in $17 \%$ of patients, which is similar to the rates reported in other studies $(23,24)$. The American Society of Clinical Oncology guidelines state that there is insufficient evidence for using CA19-9 in the management of patients with CRC (25). However, a number 
Table I. Patient characteristics.

\begin{tabular}{|c|c|}
\hline Variable & \\
\hline Median age (range), years & $73(30-94)$ \\
\hline \multicolumn{2}{|l|}{ Gender, n (\%) } \\
\hline Female & $164(41.5)$ \\
\hline Male & $231(58.5)$ \\
\hline \multicolumn{2}{|l|}{ ASA physical status, n (\%) } \\
\hline I & $32(8.1)$ \\
\hline II & $296(74.9)$ \\
\hline III & $67(17.0)$ \\
\hline \multicolumn{2}{|l|}{ Site of tumor, n (\%) } \\
\hline Right colon & $129(32.7)$ \\
\hline Left colon & $191(48.3)$ \\
\hline Rectum & $75(19.0)$ \\
\hline Maximum tumor diameter, median (range), $\mathrm{mm}$ & $45(8-185)$ \\
\hline \multicolumn{2}{|l|}{ Tumor depth, n (\%) } \\
\hline $\mathrm{T} 1$ & $52(13.2)$ \\
\hline $\mathrm{T} 2$ & $47(11.9)$ \\
\hline $\mathrm{T} 3$ & $237(60.0)$ \\
\hline $\mathrm{T} 4$ & $50(14.9)$ \\
\hline \multicolumn{2}{|l|}{ Lymph node metastasis, $\mathrm{n}(\%)$} \\
\hline No & $229(58.0)$ \\
\hline N1 & $115(29.1)$ \\
\hline $\mathrm{N} 2$ & $51(12.9)$ \\
\hline \multicolumn{2}{|l|}{ Histology, n (\%) } \\
\hline Differentiated & $377(95.4)$ \\
\hline Undifferentiated & $18(4.6)$ \\
\hline \multicolumn{2}{|l|}{ Lymphatic involvement, n (\%) } \\
\hline Absent & $116(29.4)$ \\
\hline Present & $279(70.6)$ \\
\hline \multicolumn{2}{|l|}{ Venous involvement, $\mathrm{n}(\%)$} \\
\hline Absent & $354(89.6)$ \\
\hline Present & $41(10.4)$ \\
\hline \multicolumn{2}{|l|}{ Hematogenous metastasis, $\mathrm{n}(\%)$} \\
\hline Absent & $351(88.9)$ \\
\hline Present & $44(11.1)$ \\
\hline \multicolumn{2}{|l|}{ Peritoneal metastasis, n (\%) } \\
\hline $\mathrm{P} 0$ & $383(97.0)$ \\
\hline P1 & $5(1.2)$ \\
\hline $\mathrm{P} 2$ & $5(1.2)$ \\
\hline $\mathrm{P} 3$ & $2(0.5)$ \\
\hline \multicolumn{2}{|l|}{ Stage* } \\
\hline I & $79(20.0)$ \\
\hline II & $142(36.0)$ \\
\hline III & $124(31.4)$ \\
\hline IV & $50(12.6)$ \\
\hline Median CEA (range), ng/dl & $4.2(0.5-6245)$ \\
\hline Median CA19-9 (range), U/ml & $10.3(<2-5846)$ \\
\hline
\end{tabular}

ASA, American Society of Anesthesiologists; CEA, carcinoembryonic antigen; CA19-9, carbohydrate antigen 19-9. *Union for International Cancer.

of studies have demonstrated the clinical significance of CA19-9 in CRC $(23,24,26,27)$. Serum CA19-9, especially a high preoperative level, was found to be an important predictor of disease recurrence $(23,26)$, and an elevated CA19-9 level was correlated with peritoneal recurrence after
Table II. Association between clinicopathological factors and peritoneal carcinomatosis by univariate analysis.

\begin{tabular}{|c|c|c|c|}
\hline \multirow[b]{2}{*}{ Variable } & \multicolumn{2}{|c|}{$\begin{array}{c}\text { Peritoneal carcinomatosis, } \\
\mathrm{n}(\%)\end{array}$} & \multirow[b]{2}{*}{$p$-Value } \\
\hline & Absent & Present & \\
\hline \multicolumn{4}{|l|}{ Age } \\
\hline$<75$ Years & $212(55.4)$ & $8(66.7)$ & \multirow[t]{2}{*}{0.56} \\
\hline$\geq 75$ Years & $171(44.6)$ & $4(33.3)$ & \\
\hline \multicolumn{4}{|l|}{ Gender } \\
\hline Female & $160(41.8)$ & $4(33.3)$ & \multirow[t]{2}{*}{0.77} \\
\hline Male & $223(58.2)$ & $8(66.7)$ & \\
\hline \multicolumn{4}{|l|}{ ASA physical status } \\
\hline I, II & $319(83.3)$ & $10(83.3)$ & \multirow[t]{2}{*}{1.00} \\
\hline III & $64(16.7)$ & $2(16.7)$ & \\
\hline \multicolumn{4}{|l|}{ Site of tumor } \\
\hline Right colon & $121(31.6)$ & $8(66.7)$ & \multirow[t]{3}{*}{0.057} \\
\hline Left colon & $188(41.1)$ & $3(25.0)$ & \\
\hline Rectum & $74(19.3)$ & $1(8.3)$ & \\
\hline \multicolumn{4}{|c|}{ Maximum tumor diameter (mm) } \\
\hline$<50$ & $215(56.1)$ & $4(33.3)$ & \multirow[t]{2}{*}{0.15} \\
\hline$\geq 50$ & $168(43.9)$ & $8(66.7)$ & \\
\hline \multicolumn{4}{|l|}{ Tumor depth } \\
\hline $\mathrm{T} 1-3$ & $331(86.4)$ & $5(41.7)$ & \multirow[t]{2}{*}{$<0.001$} \\
\hline $\mathrm{T} 4$ & $52(13.6)$ & $7(58.3)$ & \\
\hline \multicolumn{4}{|c|}{ Lymph node metastasis } \\
\hline N0, 1 & $342(89.3)$ & $8(66.7)$ & \multirow[t]{2}{*}{0.037} \\
\hline N2 & $41(10.7)$ & $4(33.3)$ & \\
\hline \multicolumn{4}{|l|}{ Histology } \\
\hline Differentiated & $366(95.6)$ & $11(91.7)$ & \multirow[t]{2}{*}{0.43} \\
\hline Undifferentiated & $17(4.4)$ & $1(8.3)$ & \\
\hline \multicolumn{4}{|c|}{ Lymphatic involvement } \\
\hline Absent & $115(30.0)$ & $1(8.3)$ & \multirow[t]{2}{*}{0.19} \\
\hline Present & $268(70.0)$ & $11(91.7)$ & \\
\hline \multicolumn{4}{|l|}{ Venous involvement } \\
\hline Absent & $345(90.1)$ & $9(75.0)$ & \multirow[t]{2}{*}{0.12} \\
\hline Present & $38(9.9)$ & $3(25.0)$ & \\
\hline \multicolumn{4}{|c|}{ Hematogenous metastasis } \\
\hline Absent & $345(90.1)$ & $6(50.0)$ & \multirow[t]{2}{*}{$<0.001$} \\
\hline Present & $38(9.9)$ & $6(50.0)$ & \\
\hline \multicolumn{4}{|l|}{ CEA } \\
\hline$<5 \mathrm{ng} / \mathrm{dl}$ & $222(58.0)$ & $5(41.7)$ & 0.38 \\
\hline$\geq 5 \mathrm{ng} / \mathrm{dl}$ & $161(42.0)$ & $7(58.3)$ & \\
\hline CA19-9 & & & \\
\hline$<37 \mathrm{U} / \mathrm{ml}$ & $324(84.6)$ & $4(33.3)$ & $<0.001$ \\
\hline$\geq 37 \mathrm{U} / \mathrm{ml}$ & $59(15.4)$ & $8(66.7)$ & \\
\hline
\end{tabular}

ASA, American Society of Anesthesiologists; CEA, carcinoembryonic antigen; CA19-9, carbohydrate antigen 19-9.

curative resection of CRC $(23,24)$. The preoperative CA199 level may also be useful for predicting the prognosis of patients with stage IV CRC (27). In this study, an elevated preoperative CA19-9 level was the only significant risk factor for synchronous PC in patients with CRC. 
Table III. Association between clinicopathological factors and peritoneal carcinomatosis by multivariate analysis.

\begin{tabular}{llll}
\hline Variable & OR & $95 \%$ CI & $p$-Value \\
\hline Tumor depth: T4 vs. T1-3 & 3.11 & $0.79-12.20$ & 0.11 \\
Lymph node metastasis: N2 vs. N0,1 & 1.60 & $0.38-6.65$ & 0.52 \\
Hematogenous metastasis: Present $v s$. absent & 3.29 & $0.88-12.30$ & 0.076 \\
CA19-9: $\geq 37$ vs. $<37 \mathrm{U} / \mathrm{ml}$ & 5.03 & $1.29-19.60$ & 0.020 \\
\hline
\end{tabular}

OR, Odds ratio; CI, confidence interval; CA19-9, carbohydrate antigen 19-9.

Previous studies have shown that the sensitivity of CT in detecting peritoneal implants is influenced by lesion size $(12,14)$; small nodules $(<0.5 \mathrm{~cm})$ were visualized by CT with only $11 \%$ sensitivity (14). In the present study, $50 \%$ of patients with PC were identified as having no PC in the preoperative CT evaluation, but had high preoperative CA19-9 level; two of the patients had multiple hepatic metastases, one had multiple hepatic and lung metastases, and the others had PC alone. The sensitivity and specificity of an elevated preoperative CA19-9 level for detecting synchronous PC were $67 \%$ and $85 \%$, respectively; the positive and negative predictive values were $14 \%$ and $99 \%$, respectively; and the accuracy was $84 \%$ (data not shown). These results suggest that the preoperative CA19-9 level may be useful in predicting synchronous PC in patients with CRC; in fact, several reports indicate that it may have predictive value for identifying PC in patients with gastric cancer (28-30).

CA19-9 (sialyl-Lewis[a]) expressed on tumor cells has been implicated in the mechanisms underlying distant metastasis and peritoneal spread (31-36). Tumor metastasis is similar to leukocyte trafficking in that tumor cells circulating in the blood extravasate and populate new tissues using the same types of adhesion molecule $(32,33)$. In cancer cell lines expressing sialyl-Lewis[x] and/or sialylLewis[a], tumor cell adhesion to the endothelium expressing E-selectin was correlated with the expression level of sialyl-Lewis, an E-selectin ligand (34). Furthermore, tumor cells activate platelets that express Pselectin, which interacts with sialyl-Lewis; P-selectindependent tumor cell adhesion to platelets leads to tumor cell aggregation and microembolism (35). Thus, interaction of CA19-9 with selectins is important in hematogenous metastasis. With regards to peritoneal seeding, CA19-9 expressed by pancreatic adenocarcinoma cells was shown to interact with E-selectin constitutively expressed on human mesothelial and endothelial cells in the peritoneum. The interaction of pancreatic adenocarcinoma cells expressing CA19-9 with E- and P- selectins was demonstrated by dynamic flow assays and flow cytometry, with CA19-9 shown to be the main E-selectin ligand. In addition, peritoneal metastasis was reduced in E- and P-

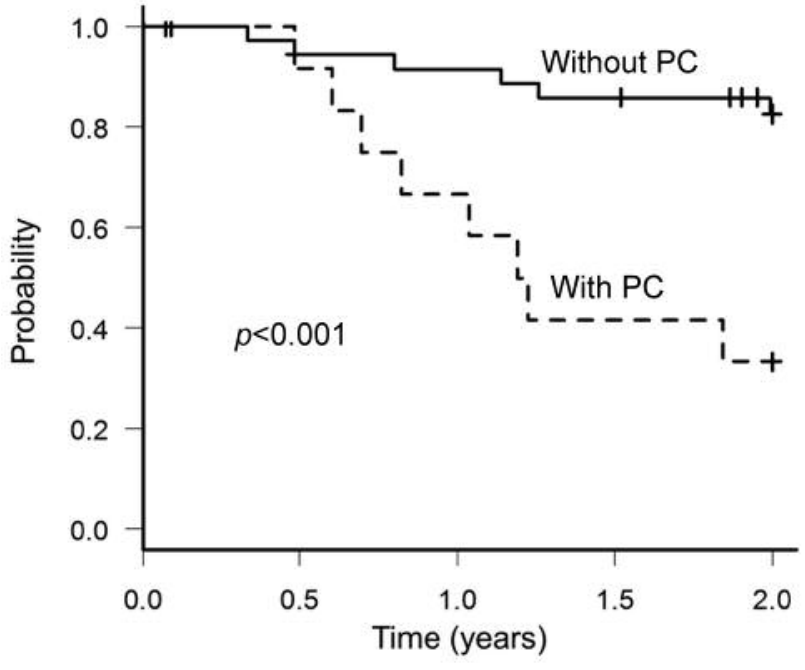

Figure 1. Survival curves of patients with stage IV colorectal cancer who underwent resection of the primary lesion. Kaplan-Meier estimates of the 2-year overall survival of patients with and without peritoneal carcinomatosis $(P C)$ are shown.

selectin double knockout mice compared to wild-type mice in a xenograft model (36).

There were caveats and limitations to this study. The serum CA19-9 level is influenced by factors besides PC; individuals with a Lea-b-phenotype (i.e. lacking the Lewis antigen glycosyltransferase) are unable to synthesize CA19$9(5-10 \%$ of the population) $(37,38)$, while those with benign biliary tract disease, acute or chronic pancreatitis, and malignancies including pancreatic, biliary tree, stomach, liver, or lung cancer can exhibit an elevated CA19-9 level (5). Furthermore, this study is limited by its retrospective design and small sample size, and was carried out at a single institution; additional studies with larger populations are, therefore, required to confirm our findings.

In conclusion, the results presented here indicate that the preoperative serum CA19-9 level is a useful indicator of synchronous PC. This can inform postoperative treatment strategies and is useful for predicting the prognosis of patients with CRC. 


\section{Acknowledgements}

The Authors declare that there are no conflicts of interest.

\section{References}

1 Torre LA, Bray F, Siegel RL, Ferlay J, Lortet-Tieulent J and Jemal A: Global cancer statistics, 2012. CA Cancer J Clin 65: 87-108, 2015.

2 Franko J, Shi Q, Goldman CD, Pockaj BA, Nelson GD, Goldberg RM, Pitot HC, Grothey A, Alberts SR and Sargent DJ: Treatment of colorectal peritoneal carcinomatosis with systemic chemotherapy: a pooled analysis of north central cancer treatment group phase III trials n9741 and n9841. J Clin Oncol 30: 263-267, 2012.

3 Tebbutt NC, Norman AR, Cunningham D, Hill ME, Tait D, Oates $\mathrm{J}$, Livingston $\mathrm{S}$ and Andreyev J: Intestinal complications after chemotherapy for patients with unresected primary colorectal cancer and synchronous metastases. Gut 52: 568-573, 2003.

4 Katoh H, Yamashita K, Kokuba Y, Satoh T, Ozawa H, Hatate K, Ihara A, Nakamura T, Onosato W and Watanabe M: Surgical resection of stage IV colorectal cancer and prognosis. World J Surg 32: 1130-1137, 2008 .

$5 \mathrm{Yu} \mathrm{H}$, Son GM and Joh YG: The clinical significance of preoperative serum levels of carbohydrate antigen 19-9 in colorectal cancer. J Korean Surg Soc 84: 231-237, 2013.

6 Watanabe T, Itabashi M, Shimada Y, Tanaka S, Ito Y, Ajioka Y, Hamaguchi T, Hyodo I, Igarashi M, Ishida H, Ishihara S, Ishiguro M, Kanemitsu Y, Kokudo N, Muro K, Ochiai A, Oguchi M, Ohkura Y, Saito Y, Sakai Y, Ueno H, Yoshino T, Boku N, Fujimori T, Koinuma N, Morita T, Nishimura G, Sakata Y, Takahashi K, Tsuruta O, Yamaguchi T, Yoshida M, Yamaguchi N, Kotake K and Sugihara K; Japanese Society for Cancer of the Colon and Rectum: Japanese Society for Cancer of the Colon and Rectum (JSCCR) Guidelines 2014 for treatment of colorectal cancer. Int J Clin Oncol 20: 207-239, 2015.

7 Jayne DG, Fook S, Loi C and Seow-Choen F: Peritoneal carcinomatosis from colorectal cancer. Br J Surg 89: 1545-1550, 2002.

8 Lemmens VE, Klaver YL, Verwaal VJ, Rutten HJ, Coebergh JW and de Hingh IH: Predictors and survival of synchronous peritoneal carcinomatosis of colorectal origin: a populationbased study. Int J Cancer 128: 2717-2725, 2011.

9 Segelman J, Granath F, Holm T, Machado M, Mahteme H and Martling A: Incidence, prevalence and risk factors for peritoneal carcinomatosis from colorectal cancer. Br J Surg 99: 699-705, 2012.

10 Glehen O, Osinsky D, Cotte E, Kwiatkowski F, Freyer G, Isaac S, Trillet-Lenoir V, Sayag-Beaujard AC, François Y, Vignal J and Gilly FN: Intraperitoneal chemohyperthermia using a closed abdominal procedure and cytoreductive surgery for the treatment of peritoneal carcinomatosis: morbidity and mortality analysis of 216 consecutive procedures. Ann Surg Oncol 10: 863-869, 2003.

11 Al-Shammaa HA, Li Y and Yonemura Y: Current status and future strategies of cytoreductive surgery plus intraperitoneal hyperthermic chemotherapy for peritoneal carcinomatosis. World J Gastroenterol 14: 1159-1166, 2008.

12 de Bree E, Koops W, Kröger R, van Ruth S, Witkamp AJ and Zoetmulder FA: Peritoneal carcinomatosis from colorectal or appendiceal origin: correlation of preoperative CT with intraoperative findings and evaluation of interobserver agreement. J Surg Oncol 86: 64-73, 2004.

13 Esquivel J, Chua TC, Stojadinovic A, Melero JT, Levine EA, Gutman M, Howard R, Piso P, Nissan A, Gomez-Portilla A, Gonzalez-Bayon L, Gonzalez-Moreno S, Shen P, Stewart JH, Sugarbaker PH, Barone RM, Hoefer R, Morris DL, Sardi A and Sticca RP: Accuracy and clinical relevance of computed tomography scan interpretation of peritoneal cancer index in colorectal cancer peritoneal carcinomatosis: A multi-institutional study. J Surg Oncol 102: 565-570, 2010.

14 Koh JL, Yan TD, Glenn D and Morris DL: Evaluation of preoperative computed tomography in estimating peritoneal cancer index in colorectal peritoneal carcinomatosis. Ann Surg Oncol 16: 327-333, 2009.

15 Dromain C, Leboulleux S, Auperin A, Goere D, Malka D, Lumbroso J, Schumberger M, Sigal R and Elias D: Staging of peritoneal carcinomatosis: Enhanced CT vs. PET/CT. Abdom Imaging 33: 87-93, 2008.

16 Ryu YJ, Kim CH, Kim HJ, Kang H, Lim SW, Huh JW, Ju JK, Kim YJ and Kim HR: Clinical significance of serial serum carcinoembryonic antigen values for treating rectal cancer with preoperative chemoradiotherapy. J Korean Soc Coloproctol 28: 205-212, 2012.

17 Sobin LH, Gospodarowicz MK and Wittekind C (eds.); International Union Against Cancer (UICC): TNM Classification of Malignant Tumours. Seventh Edition. Chichester, WileyBlackwell, 2010.

18 Japanese Society for Cancer of the Colon and Rectum: Japanese classification of colorectal carcinoma. Second Edition. Tokyo, Kanehara \& Co., 2009.

19 Kanda Y: Investigation of the freely available easy-to-use software 'EZR' for medical statistics. Bone Marrow Transplant 48: 452-458, 2013.

20 Brücher BL, Piso P, Verwaal V, Esquivel J, Derraco M, Yonemura Y, Gonzalez-Moreno S, Pelz J, Königsrainer A, Ströhlein M, Levine EA, Morris D, Bartlett D, Glehen O, Garofalo A and Nissan A: Peritoneal carcinomatosis: cytoreductive surgery and HIPEC - overview and basics. Cancer Invest 30: 209-224, 2012.

21 Kobayashi H, Kotake K, Funahashi K, Hase K, Hirata K, Iiai T, Kameoka S, Kanemitsu Y, Maeda K, Murata A, Ohue M, Shirouzu K, Takahashi K, Watanabe T, Yano H, Yatsuoka T, Hashiguchi Y and Sugihara K; Study Group for Peritoneal Metastasis from Colorectal Cancer by the Japanese Society for Cancer of the Colon and Rectum: Clinical benefit of surgery for stage IV colorectal cancer with synchronous peritoneal metastasis. J Gastroenterol 49: 646-654, 2014.

22 Magnani JL, Nilsson B, Brockhaus M, Zopf D, Steplewski Z, Koprowski $\mathrm{H}$ and Ginsburg V: A monoclonal antibody-defined antigen associated with gastrointestinal cancer is a ganglioside containing sialylated lacto-N-fucopentaose II. J Biol Chem 257: 14365-14369, 1982.

23 Park IJ, Choi GS and Jun SH: Prognostic value of serum tumor antigen CA19-9 after curative resection of colorectal cancer. Anticancer Res 29: 4303-4308, 2009.

24 Takakura Y, Ikeda S, Imaoka Y, Urushihara T and Itamoto T: An elevated preoperative serum carbohydrate antigen 19-9 level is a significant predictor for peritoneal dissemination and poor survival in colorectal cancer. Colorectal Dis 17: 417-425, 2015. 
25 Locker GY, Hamilton S, Harris J, Jessup JM, Kemeny N, Macdonald JS, Somerfield MR, Hayes DF, Bast RC and ASCO: ASCO 2006 update of recommendations for the use of tumor markers in gastrointestinal cancer. J Clin Oncol 24: 5313-5327, 2006.

26 Yang SH, Jiang JK, Chang SC, Juang CJ and Lin JK: Clinical significance of CA19-9 in the follow-up of colorectal cancer patients with elevated preoperative serum CA19-9. Hepatogastroenterology 60: 1021-1027, 2013.

27 Yamashita $\mathrm{K}$ and Watanabe M: Clinical significance of tumor markers and an emerging perspective on colorectal cancer. Cancer Sci 100: 195-199, 2009.

28 Ohi M, Mori K, Toiyama Y, Mohri Y, Okigami M, Yasuda H, Saigusa S, Tanaka K, Inoue Y and Kusunoki M: Preoperative prediction of peritoneal metastasis in gastric cancer as an indicator for neoadjuvant treatment. Anticancer Res 35: 35113518, 2015.

29 Hwang GI, Yoo CH, Sohn BH, Shin JH, Park YL, Kim HD, Kim YS, Han WK and Pae WK: Predictive value of preoperative serum CEA, CA19-9 and CA125 levels for peritoneal metastasis in patients with gastric carcinoma. Cancer Res Treat 36: 178$181,2004$.

30 Han ES, Lee HH, Lee JS, Song KY, Park CH and Jeon HM: At which stage of gastric cancer progression do levels of carcinoembryonic antigen and carbohydrate antigen 19-9 increase? Application in advanced gastric cancer treatment. J Gastric Cancer 14: 123-128, 2014.

31 Dabelsteen E: Cell surface carbohydrates as prognostic markers in human carcinomas. J Pathol 179: 358-369, 1996.

32 Gahmberg CG, Kotovuori $\mathrm{P}$ and Tontti E: Cell surface carbohydrate in cell adhesion. Sperm cells and leukocytes bind to their target cells through specific oligosaccharide ligands. APMIS Suppl 27: 39-52, 1992.
33 Varki A: Selectin ligands. Proc Natl Acad Sci USA 91: 73907397, 1994.

34 Takada A, Ohmori K, Yoneda T, Tsuyuoka K, Hasegawa A, Kiso $\mathrm{M}$ and Kannagi R: Contribution of carbohydrate antigens sialyl Lewis A and sialyl Lewis $X$ to adhesion of human cancer cells to vascular endothelium. Cancer Res 53: 354-361, 1993.

35 Martini F, Guadagni F, Lenti L, D'Alessandro R, Aloe S, Roselli M, Gazzaniga PP and Ferroni P: CA19-9 monosialoganglioside content of human colorectal tumor cells correlates with tumor cellinduced platelet aggregation. Anticancer Res 20: 1609-1614, 2000.

36 Gebauer F, Wicklein D, Stübke K, Nehmann N, Schmidt A, Salamon J, Peldschus K, Nentwich MF, Adam G, Tolstonog G, Bockhorn M, Izbicki JR, Wagener $\mathrm{C}$ and Schumacher U: Selectin binding is essential for peritoneal carcinomatosis in a xenograft model of human pancreatic adenocarcinoma in pfp-/rag2-- mice. Gut 62: 741-750, 2013.

37 Tempero MA, Uchida E, Takasaki H, Burnett DA, Steplewski Z and Pour PM: Relationship of carbohydrate antigen 19-9 and Lewis antigens in pancreatic cancer. Cancer Res 47: 5501-5503, 1987.

38 Lamerz R: Role of tumour markers, cytogenetics. Ann Oncol 10(Suppl 4): 145-149, 1999. 